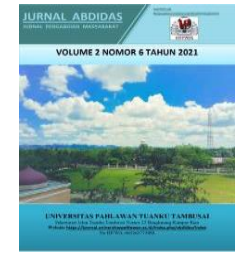

\title{
Pelatihan Membatik bagi Kelompok Ibu Rumah Tangga Nagari Cubadak Kabupaten Tanah Datar
}

\author{
Taufik Akbar $^{1 \bowtie}$, Bambang Wijaksana ${ }^{2}$, Wardi Metro ${ }^{3}$, Ahmad Bahrudin $^{4}$, Hendratno $^{5}$ \\ Kriya Seni, Institut Seni Indonesia Padangpanjang, Indonesia ${ }^{1,4,5}$ \\ Seni Musik, Institut Seni Indonesia Padangpanjang, Indonesia ${ }^{2}$ \\ Seni Tari, Institut Seni Indonesia Padangpanjang, Indonesia ${ }^{3}$ \\ E-mail : taufik723@gmail.com ${ }^{1}$ bambangwijaksana@isi-padangpanjang.ac.id ${ }^{2}$ wardimetro@isi- $^{3}$ \\ padangpanjang.ac.id ${ }^{3} \underline{\text { ahmadbahrudin @isi-padangpanjang.ac.id }}^{4} \underline{\text { hendratno@isi-padangpanjang.ac.id }}^{5}$
}

\begin{abstract}
Abstrak
Batik adalah sebuah karya seni Indonesia dan juga salah satu komoditi ekonomi kreatif. Keberadaannya memberi dampak positif bagi ekonomi masyarakat serta mendukung sektor pariwisata, Kegiatan pengabdian masyarakat ini adalah berupa pelatihan batik bagi kelompok Ibu-ibu rumah tangga di Nagari Cubadak, Kabupaten Tanah Datar, Sumatera Barat. Tujuan pengabdian masyarakat ini adalah untuk memberikan keterampilan membatik dan membuka peluang wirausaha batik bagi masyarakat setempat. Metode yang digunakan dalam kegiatan adalah demonstrasi dan pelatihan. Hasil kegiatan menunjukkan antusias peserta yang tinggi untuk membatik dengan motif ragam hias buah nangka dan coklat sebagai ciri khas kearifan lokal daerah.
\end{abstract}

Kata kunci: batik, ekonomi kreatif, pariwisata

Abstract

Batik is an Indonesian artwork and also one of the commodities of the creative economy. The existence has a positive impact on the community's economy and supports the tourism sector. This community service activity is a training of batik process to housewives groups in Cubadak Village, Tanah Datar District, West Sumatera Province. The purpose of its activities is to provide batik skills and open batik entrepreneurship opportunities for the local community. The method of community service programs uses demonstrations, and training. The output of the program show high enthusiastic of all participant to learn the batik process with jackfruit and chocolate motif's ornament as a character of local wisdom.

Keywords: batik, creative economy, tourism

Copyright (c) 2021 Taufik Akbar, Bambang Wijaksana, Wardi Metro, Ahmad Bahrudin, Hendratno $\triangle$ Corresponding author

Address : Institut Seni Indonesia Padangpanjang

Email : taufik723@gmail.com

ISSN 2721- 9224 (Media Cetak)

DOI $\quad:$ https://doi.org/10.31004/abdidas.v2i6.473

ISSN 2721- 9216 (Media Online) 
1332 Pelatihan Membatik bagi Kelompok Ibu Rumah Tangga Nagari Cubadak Kabupaten Tanah Datar Taufik Akbar, Bambang Wijaksana, Wardi Metro, Ahmad Bahrudin, Hendratno

DOI: https://doi.org/10.31004/abdidas.v2i6.473

\section{PENDAHULUAN}

Batik merupakan salah satu hasil kesenian tradisional Indonesia yang telah diakui dunia. Keterampilan membatik diwariskan turun temurun oleh nenek moyang Indonesia hingga sekarang. Perjalanan batik Indonesia telah mengalami perubahan dan perkembangan yang panjang. Penggunaan batik dengan motif tertentu bahkan sangat diatur pada zaman kerajaan-kerajaan di nusantara. Dapat dikatakan batik juga sudah menjadi penanda strata sosial pada saat itu. Motifmotif batik tradisional Indonesia juga mengandung makna dan nilai-nilai filosofis yang dilatar belakangi oleh kepercayaan dan kebudayaan masyarakat pemakainya.

Seiring perkembangan zaman batik tidak lagi dipandang sebagai karya seni atau pakaian yang eksklusif. Batik sudah menjadi karya wastra Indonesia yang merakyat, selain itu motif-motif batik baru pun berkembang sesuai dengan kreativitas dan kemajuan zaman. Batik menjadi lebih merakyat dimulai sekitar abad ke-19 (MD, 2009). Tidak hanya dari sisi budaya, dari sisi ekonomi batik saat ini juga menjadi produk kriya yang memiliki peluang dan nilai ekonomis bagi masyarakat luas.

Batik sebagai sebuah produk yang bernilai ekonomis ditandai dengan berkembangnya UMKM (Usaha Mikro Kecil Menengah) yang memroduksi dan menjual berbagai produk batik. Batik dapat dikatakan sudah menjadi aset seni budaya Indonesia dalam ranah industri kreatif yang berdaya saing ( Nurcahayati et al., 2018) Masing-masing UMKM memiliki keunikan tersendiri pada produk batiknya. Umumnya keunikan tersebut dapat dilihat dari corak motif batik yang berciri khas kearifan lokal daerah masing-masing.

Sejak ditetapkan UNESCO sebagai salah satu warisan budaya dunia, pemerintah Indonesia terus berusaha mempopulerkan batik ke seluruh daerah dan propinsi di Indonesia. Setiap daerah dapat menciptakan dan mengembangkan batik dengan karakter daerah tersendiri (Yulimarni, et al., 2021). Usaha ini selain bertujuan sebagai pelestarian budaya juga untuk menumbuh kembangkan minat wirausaha masyarakat terhadap batik dan mendorong terciptanya UMKM batik sehingga nantinya dapat mendukung ekonomi masyarakat. Selain itu Kehadiran batik juga dapat menunjang sektor pariwisata suatu daerah.

Kabupaten Tanah Datar di Sumatera Barat saat ini sedang mengembangkan pariwisata dan ekonomi kreatif masyarakatnya. Potensi wisata kabupaten ini antara lain adalah wisata alam, sejarah maupun budaya (Permana et al., 2019). Untuk menunjang tujuan tersebut setiap Nagari (wilayah pemerintahan setingkat desa) di Tanah Datar berusaha menciptakan keunikan daerah masing-masing yang menarik dan dapat dijual pada wisatawan yang berkunjung, contohnya adalah dengan menciptakan kerajinan batik. Nagari Cubadak adalah salah satu Nagari di Kabupaten Tanah Datar yang sedang berusaha memberdayakan masyarakatnya untuk menciptakan dan mengembangkan kerajinan batik, khususnya kelompok ibu rumah tangga. Kelompok Ibu Rumah Tangga yang umumnya tidak bekerja diharapkan dapat mengisi waktu luangnya di selasela mengurus rumah tangga dengan membuat 
1333 Pelatihan Membatik bagi Kelompok Ibu Rumah Tangga Nagari Cubadak Kabupaten Tanah Datar Taufik Akbar, Bambang Wijaksana, Wardi Metro, Ahmad Bahrudin, Hendratno

DOI: https://doi.org/10.31004/abdidas.v2i6.473

kerajinan batik. Dengan latar belakang situasi yang demikian maka dilakukanlah kegiatan pengabdian kepada masyarakat mengasah keterampilan guna mengajarkan dan meningkatkan keterampilan Ibu-Ibu Rumah Tangga Nagari Cubadak dalam membatik.

\section{METODE}

Kegiatan pengabdian pelatihan keterampilan membatik ini merupakan kegiatan lanjutan. Para peserta yang mengikuti kegiatan ini terdiri dari peserta yang sudah pernah membatik dan peserta baru yang baru mengenal proses membatik. Target kegiatan ini adalah selain melatih keterampilan peserta dalam membatik juga mengembangkan motif-motif batik baru yang berlatar belakang potensi daerah.

Metode yang digunakan dalam kegiatan pengabdian ini adalah berupa ceramah, demonstrasi dan pelatihan keterampilan. Metode ceramah dilakukan dengan memberikan teori tentang batik meliputi alat, bahan, desain, peluang serta potensi tentang kerajinan batik. Metode demonstrasi adalah dengan unjuk kerja atau peragaan keterampilan. Demonstrasi dilakukan dengan dua tahap yaitu demonstrasi mendesain dan demonstrasi proses membatik. Setelah para peserta melihat demonstrasi yang diperagakan instruktur, mereka kemudian mulai melakukan kegiatan yang didemonstrasikan baik mendesain hingga membatik. Pada tahap merancang desain motif batik para peserta diarahkan untuk dapat merancang desain motif yang mencerminkan identitas, potensi serta kearifan lokal Nagari Cubadak. Dari proses ini didapatlah desain motif batik yang terinspirasi dari bentuk buah nangka dan coklat. Hal ini dikarenakan kedua buah ini merupakan potensi dari daerah ini. Berikut ini adalah tahapan kegiatan pelatihan yang dilakukan:

1. Persiapan dan pengenalan alat dan bahan pelatihan batik.

2. Pemberian materi tentang teori batik dan seluk beluk batik pada peserta.

3. Instruktur unjuk kerja mendemonstrasikan proses mendesain motif batik.

4. Peserta merancang dan menkreasikan motif batik masing-masing.

5. Peserta memindahkan rancangan desain motif pada kain.

6. Instruktur mendemonstrasikan proses membatik (mencanting).

7. Peserta melakukan proses membatik (mencanting).

8. Instruktur mendemonstrasikan proses finishing karya batik.

9. Peserta melakukan proses finishing karya batik masing-masing.

10. Evaluasi karya batik peserta.

Pada proses finishing karya batik tahapan proses yang dilatihkan pada peserta adalah tahapan mewarna, pemberian waterglass dan kemudian melorot. Teknik membatik yang digunakan pada pelatihan ini adalah teknik batik tulis.

Teknik batik tulis dipilih karena dapat mengasah keterampilan tangan peserta agar terbiasa membatik. Keterampilan tangan dalam membatik khususnya mencanting merupakan keterampilan utama pertama dan utama yang harus dikuasi oleh setiap pembatik atau orang yang akan belajar membatik. Sebagai sebuah keterampilan. 
1334 Pelatihan Membatik bagi Kelompok Ibu Rumah Tangga Nagari Cubadak Kabupaten Tanah Datar Taufik Akbar, Bambang Wijaksana, Wardi Metro, Ahmad Bahrudin, Hendratno

DOI: https://doi.org/10.31004/abdidas.v2i6.473

Dengan teknik batik tulis tangan peserta akan dipaksa untuk sering praktik mencanting hingga nantinya menjadi terampil. Keterampilan merupakan sesuatu yang dapat dilatih karena seringnya diparktikkan (Taufik Akbar, Ferawati, 2020).

Jumlah peserta yang mengikuti kegiatan pelatihan membatik di Nagari Cubadak adalah 20 peserta. Para peserta membuat kain batik berukuran 1x1 meter yang dapat digunakan sebagai alas meja. Selain itu pada tahap evaluasi karya peserta dilombakan untuk dapat memotivasi peserta agar terus semangat belajar membatik kegiatan pelatihan sendiri berlangsung lebih kurang 3 hari yaitu 22, 30-31 Juli 2021, sedangkan proses evaluasi dan penilaian karya berlangsung pada tanggal 7 Agustus 2021.

\section{HASIL DAN PEMBAHASAN}

Batik Indonesia identik dengan keaneka ragaman motifnya. Tiap-tiap daerah memiliki motif batik yang berbeda-beda tergantung kearifan lokal atau potensi daerahnya masing-masing. Merancang dan mendesain motif yang otentik merupakan langkah kerja awal dalam membatik.

Pada pelatihan membatik di Nagari Cubadak ini peserta diberikan metode bagaimana menggali potensi daerah menjadi sebuah desain motif batik. Dalam hal ini potensi daerah yaitu buah nangka dan coklat dikreasikan menjadi motif batik dengan menerapkan prinsip-prinsip desain seperti kesatuan, keseimbangan dan keselarasan (harmoni). Setelah brainstorming ide dan proses kreasi mendesain dipilihlah desain motif batik dari Nagari Cubadak seperti gambar berikut:

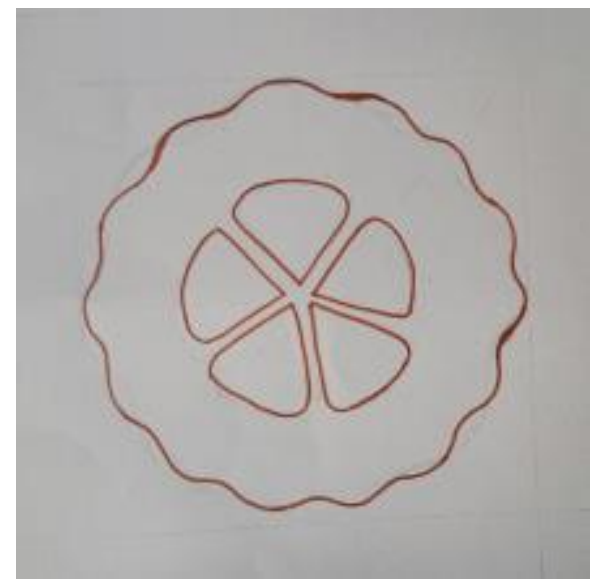

Gambar 1. Sketsa Desain Motif Batik yang Terinspirasi Dari Bentuk Buah Coklat yang Dibelah

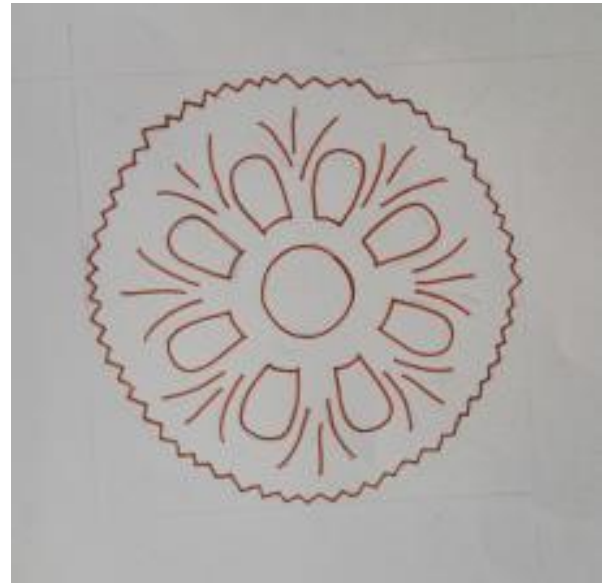

Gambar 2. Sketsa Desain Motif Batik yang Berbentuk Seperti Isi Buah yang Dibelah

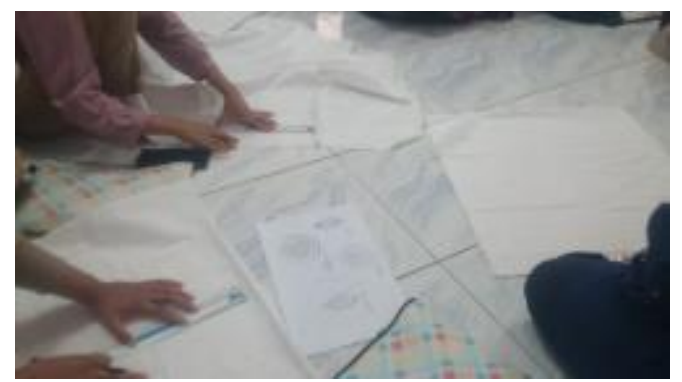

Gambar 3. Proses Mendesain Motif Batik

Langkah selanjutnya setelah menrancang motif batik adalah memindahkan motif batik pada kain dan kemudian melakukan proses pencantingan. Proses memindahkan dilakukan 
1335 Pelatihan Membatik bagi Kelompok Ibu Rumah Tangga Nagari Cubadak Kabupaten Tanah Datar Taufik Akbar, Bambang Wijaksana, Wardi Metro, Ahmad Bahrudin, Hendratno

DOI: https://doi.org/10.31004/abdidas.v2i6.473

dengan pensil sedangkan proses mencanting adalah memindahkan lilin atau malam panas pada kain dengan alat yang disebut canting. Dalam proses mencanting para peserta diberi sedikit kebebasan untuk dapat berkreasi memberi motifmotif pendamping untuk motif utama pada kain seperti daun, daunan dan motif cecek atau titiktitik. Di tahap inilah dapat diketahui gambaran bentuk motif yang ada pada kain.

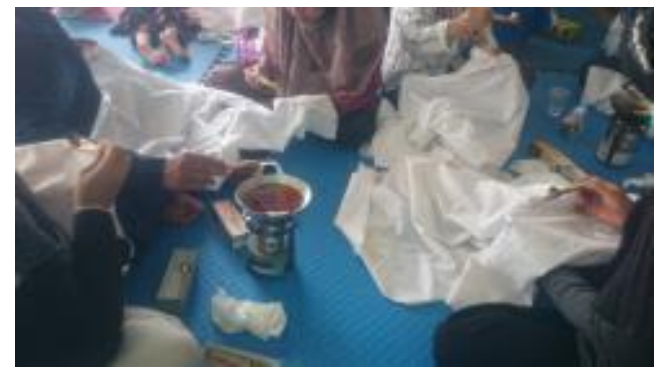

Gambar 4. Proses Mencanting Kain

Tahapan selanjutnya setelang proses pencantingan adalah dengan proses pewarnaan. Warna yang digunakan adalah pewarna kimia remasol. Semacam bubuk dengan warna tertentu yang kemudian diberi air. Teknik pewarnaan yang digunakan adalah dengan teknik colet. Teknik colet yaitu teknik membatik dengan menguaskan warna menggunakan kuas atau kapas pada kain. Teknik colet dipilih karena lebih efisien untuk menghemat penggunaan warna daripada teknik celup (Amalia \& Tjahyono, 2021). Pada proses pewarnaan peserta memilih warna utama merah dan hitam pada kain sebagai warna dasar sedangkan untuk warna motif disesuaikan dengan kreativitas msing-masing peserta.

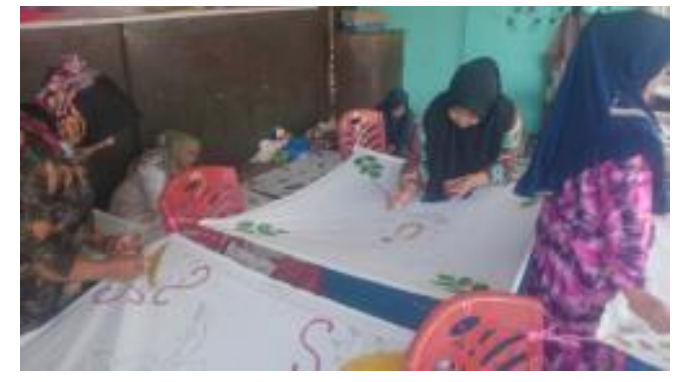

Gambar 5. Proses Mewarnai Motif Pada Kain Batik

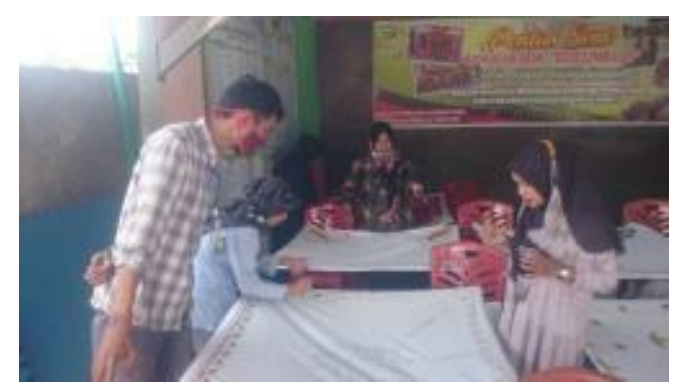

Gambar 6. Instruktur Mendampingi Peserta dalam Proses Mewarnai Motif Batik

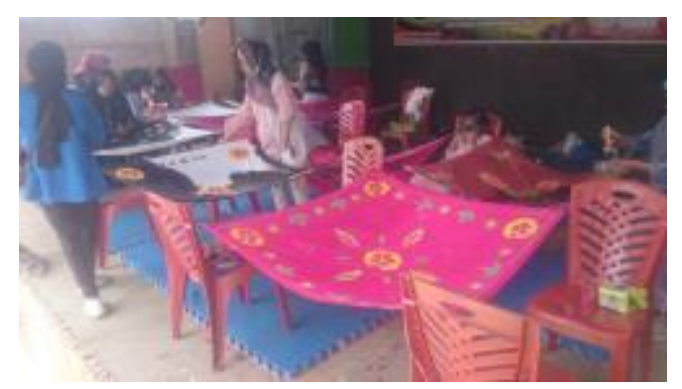

Gambar 7. Kain Batik yang Sudah Diwarnai

Setelah proses pewarnaan dilakukan maka langkah selanjutnya adalah proses finishing kain batik yang meliputi, pemberian waterglass pada kain untuk mengunci warna, penjemuran dan kemudian proses melorot (menghilangkan malam yang menempel dengan cara kain direbus dengan air panas). Setelah proses pelorotan selesai maka kain batik kemudian dibasuh dengan air bersih dan selanjutnya dapat dikeringkan Berikut ini adalah 
1336 Pelatihan Membatik bagi Kelompok Ibu Rumah Tangga Nagari Cubadak Kabupaten Tanah Datar Taufik Akbar, Bambang Wijaksana, Wardi Metro, Ahmad Bahrudin, Hendratno

DOI: https://doi.org/10.31004/abdidas.v2i6.473

gambar proses finishing dan hasil karya peserta pelatihan:

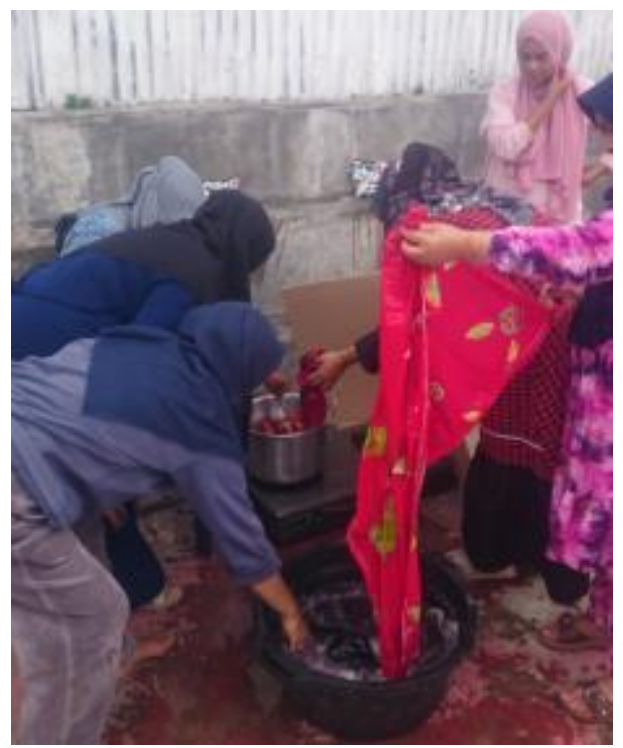

Gambar 8. Proses Melorot dan Membasuk Kain Batik

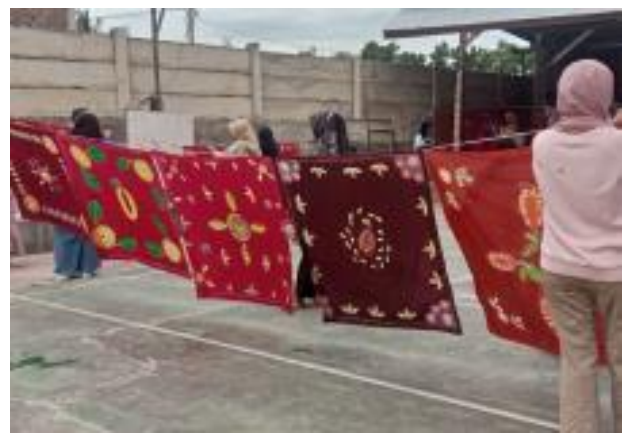

Gambar 9. Proses Menjemur Kain Batik

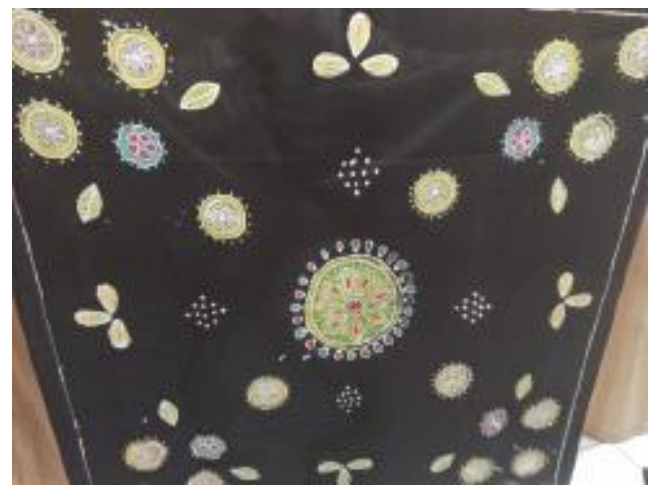

Gambar 10. Salah Satu Hasil Karya Peserta Pelatihan yang Menjadi Pemenang

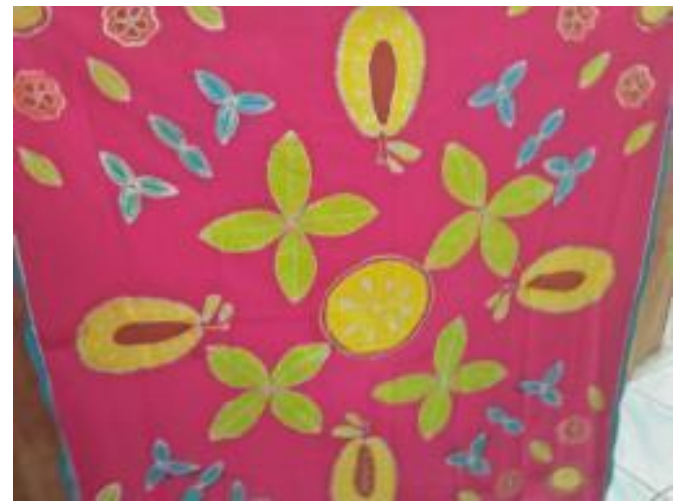

Gambar 12. Salah Satu Hasil Karya Peserta Pelatihan yang Menjadi Pemenang

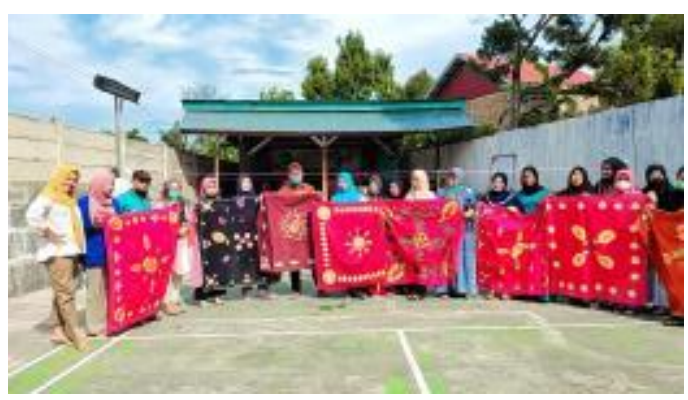

Gambar 13. Karya-karya Peserta Pelatihan Membatik

\section{SIMPULAN}

Pelatihan membatik bagi kelompok Ibu Rumah Tangga di Nagari Cubadak terlaksana dengan baik. Beberapa peserta dapat mengikuti kegiatan sepenuhnya walaupun dari segi hasil karya belum masih dapat ditingkatkan lagi. Diharapkan dengan pelatihan membatik ini keterampilan membatik para peserta semakin terasah dan bagi peserta yang baru pertama mengikuti pelatihan dapat memiliki keterampilan dasar dalam membatik. Untuk tahapan selanjutnya para peserta dapat membentuk kelompok usaha batik sendiri agar dapat dikembangkan menjadi UMKM daerah. Dengan demikian usaha pemerintah daerah Kabupaten Tanah Datar dan Nagari Cubadak untuk memberdayakan 
1337 Pelatihan Membatik bagi Kelompok Ibu Rumah Tangga Nagari Cubadak Kabupaten Tanah Datar Taufik Akbar, Bambang Wijaksana, Wardi Metro, Ahmad Bahrudin, Hendratno

DOI: https://doi.org/10.31004/abdidas.v2i6.473

masyarakatnya agar dapat membatik sebagai upaya untuk menunjang pariwisata dan ekonomi kreatif di daerah tersebut dapat terwujud.

\section{UCAPAN TERIMA KASIH}

Pelaksanaan pelatihan membatik di Nagari Cubadak ini tidak akan dapat terlaksana dengan lancar tanpa bantuan dan dukungan dari berbagai pihak. Untuk itu tidak lupa ucapan terima kasih diucapkan kepada pihak LPPMPP (Lembaga Penelitian, Pengabdian Masyarakat dan Pengembangan Pendidikan) ISI Padangpanjang, Pemerintah Kabupaten Tanah Datar khususnya Nagari Cubadak, para instruktur serta khususnya peserta pelatihan dan seluruh masyarakat Nagari Cubadak.

\section{DAFTAR PUSTAKA}

Amalia, A., \& Tjahyono, R. (2021). Penggunaan Teknologi Tepat Guna Meja Colet Batik di Rumah Kreatif De Suket. Abdimasku: Jurnal Pengabdian Masyarakat, 4(3), 339. https://doi.org/10.33633/ja.v4i3.328

MD, I. U. (2009). Batik dan Kontribusinya. Jurnal Bestari Universitas Muhamadiyah Malang, 42(1), 21-32. http://ejournal.umm.ac.id/index.php/bestari/a rticle/viewFile/91/103_umm_scientific_journ al.doc

Nurcahyanti, D., \& Bina Affanti, T. (2018). Pengembangan Desain Batik Kontemporer Berbasis Potensi Daerah Dan Kearifan Lokal. Jurnal Sosioteknologi, 17(3), 391-402. https://doi.org/10.5614/sostek.itbj.2018.17.3. 7

Permana, E. S., Triyatno, \& Nofrizal, A. Y. (2019). Pemanfaatan Network Analysis Dalam Mengidentifikasi Objek Wisata Budaya Di Kabupaten Tanah Datar. Jurnal Sains Informasi Geografi [JSIG], 2, 30-39.
Keterampilan Pemanfaatan Cangkang Telur untuk Produk Seni Kerajinan bagi Kelompok Ibu Rumah Tangga Kota Padang Panjang Taufik. Jurnal Abdidas, 1(3), 761-769.

Yulimarni, Baharudin, A., Widdiyanti, Prastawa, W., Akbar, T. (2021). Jurnal abdidas. Jurnal Abdidas, 1(3), 149-156.

Taufik Akbar, Ferawati, I. A. (2020). Pelatihan 